\title{
Glutathione and glutamate levels in the diaphragm of patients with chronic obstructive pulmonary disease
}

\author{
M.P.K.J. Engelen*, M. Orozco-Levi", N.E.P. Deutz", E. Barreiro", N. Hernández , E.F.M. Wouters*, \\ J. Gea , A.M.W.J. Schols*
}

Glutathione and glutamate levels in the diaphragm of patients with chronic obstructive pulmonary disease. M.P.K.J. Engelen, M. Orozco-Levi, N.E.P. Deutz, E. Barreiro, N. Hernández, E.F.M. Wouters, J. Gea, A.M.W.J. Schols. (C) ERS Journals Ltd 2004. ABSTRACT: Recently, decreased glutamate (Glu) and reduced glutathione (GSH) levels were reported in the quadriceps femoris of patients with chronic obstructive pulmonary disease (COPD). The aim of the present study was to investigate whether Glu and GSH levels are also modified in the diaphragm of these patients.

Nine male COPD patients (forced expiratory volume in one second (FEV1) range $28-68 \%$ of the predicted value) and seven male patients with normal pulmonary function (mean \pm SD FEV1 86 $\pm 3 \%$ pred) submitted to thoracotomy were included. Biopsy specimens were taken from the diaphragm (both groups) and the quadriceps femoris (COPD group alone) in order to assess fibre size, myosin heavy chain expression, GSH levels and amino acid profile.

The COPD group was characterised by preserved fibre size, a higher proportion of type I fibres (mean \pm SEM $70 \pm 3$ versus $26 \pm 4 \%$ ), and higher Glu and GSH content in the diaphragm compared to the quadriceps muscle. However, Glu and GSH levels were similar in diaphragm from the COPD and control groups. Glu level correlated with GSH level in both muscles. No significant correlation was found between Glu or GSH level and fibre size or proportions.

This study shows that glutamate and reduced glutathione levels are preserved in the diaphragm of chronic obstructive pulmonary disease patients. Alterations in glutamate and reduced glutathione metabolism are muscle-specific in chronic obstructive pulmonary disease, affecting the quadriceps femoris but not the diaphragm. Glutamate and reduced glutathione levels are strongly interrelated in both muscles, independent of fibre type distribution and fibre size.

Eur Respir J 2004; 23: 545-551.
Depts of *Respiratory Medicine and ${ }^{\#}$ Surgery, University Hospital Maastricht, Maastricht, the Netherlands. "Muscle Research Unit, Municipal Institute of Medical Research, and Experimental Studies Centre, Pompeu Fabra University, Barcelona, Spain.

Correspondence: M.P.K.J. Engelen, Dept of Respiratory Medicine, University Hospital Maastricht, P.O. Box 5800, 6202 AZ Maastricht, The Netherlands.

Fax: $3143 \quad 3875051$

E-mail: M.Engelen@Pul.Unimaas.NL

Keywords: Chronic obstructive pulmonary disease

diaphragm

glutamate

glutathione

Received: February 282003

Accepted after revision: November 252003

This study was supported by grants BMH4CT98-3406 and QLK6-CT-2000-00417 from the European Union, FIS 01/1324 (Spain) and a University Hospital Maastricht (Maastricht, the Netherlands) research grant.
Recent studies have reported severely decreased levels of the amino acid glutamate (Glu) in lower limb muscles of patients with chronic obstructive pulmonary disease (COPD). This reduction in Glu levels was found in both a random (mixed) COPD group [1, 2] and a homogenous group of COPD patients with emphysema [3]. The reduced Glu concentration was found to be independent of the limb muscle group studied, since a reduction in Glu concentration was found both in the tibialis anterior and quadriceps femoris [1, 2].

Further insight into the underlying causes and mechanisms of muscle Glu depletion is of importance as Glu is involved in many metabolic pathways both at rest and during exercise [4]. Glu is an important precursor for the first and rate-limiting step in the synthesis of reduced glutathione (GSH), one of the most important antioxidants in muscle. A recent study revealed reduced levels of muscle Glu and GSH in COPD patients, and a high correlation between Glu and GSH levels in both patients and controls [3]. Reduced muscle GSH levels could result in an antioxidant/oxidant imbalance, increasing the susceptibility of the muscle to oxidative stress and cell injury [5]. Avoiding intracellular Glu depletion may therefore be of clinical importance in the prevention of oxidative stressinduced muscle damage and muscle dysfunction in patients with COPD. To date, it is not known whether the reduction in
Glu and GSH levels in COPD is limited to the skeletal muscle compartment or is a generalised phenomenon affecting all striated muscles, including the diaphragm, of these patients. In addition, to the present authors' knowledge, no studies have ever reported on the amino acid concentrations of human diaphragm in healthy conditions or in COPD.

In COPD patients, an elevated proportion of myosin heavy chain (MyHC) type I (MyHC-I) fibres has been found in the diaphragm [6], whereas a decreased proportion of MyHC-I fibres has been found in peripheral skeletal muscle [7-10]. Two studies have examined the relationship between muscle amino acid concentrations and fibre type proportions. Results with respect to Glu were strikingly different between the studies. Whereas lower concentrations of Glu were found in fast-twitch rat muscle, higher concentrations were found in a separate pool of MyHC type II (MyHC-II) fibres in human vastus lateralis $[11,12]$. Therefore, the possible existence of different Glu and GSH levels in the diaphragm and quadriceps femoris of COPD patients, and the potential association with differences in fibre type, must be addressed.

It is hypothesised that a reduction in Glu and GSH levels in patients with COPD affects all striated muscles including the diaphragm, and is unrelated to changes in fibre type distribution. Therefore, in COPD patients and patients with 
normal pulmonary function submitted to thoracotomy, biopsy specimens were taken from the diaphragm and, in the COPD group, also from the quadriceps femoris in order to assess $\mathrm{MyHC}$ expression, GSH levels and amino acid profile.

\section{Methods}

\section{Study population}

Sixteen male patients (aged $62 \pm 10$ yrs) undergoing thoracotomy for localised lung neoplasm were selected for the study. The patients were systematically selected through the Lung Cancer Multidisciplinary Committee and Dept of Surgery, Hospital del Mar, Barcelona, Spain. Nine of these patients were diagnosed with COPD, as determined from a clinical history consistent with chronic bronchitis and/or emphysema, a long history of cigarette smoking and pulmonary function test results consistent with irreversible airflow obstruction (forced expiratory volume in one second (FEV1) $<80 \%$ of the predicted value and $\mathrm{FEV} 1 / \mathrm{FVC}$ ratio $<70 \%$ pred) according to European Respiratory Society criteria [13]. Exclusion criteria for both COPD and control patients included asthma, coronary disease, low body weight (body mass index $(\mathrm{BMI})<20 \mathrm{~kg} \cdot \mathrm{m}^{-2}$ ), chronic metabolic diseases (e.g. diabetes, hypo- or hyperthyroidism), orthopaedic diseases, suspected paraneoplastic or myopathic syndromes, previous abdominal or thoracic surgery, and/or treatment with steroids, hormones or cancer chemotherapy. All patients were current smokers or had a history of previous cigarette smoking (cumulative smoking index of $59 \pm 28$ versus $59 \pm 27$ packs-yrs in COPD versus control patients). The study was conducted in accordance with World Medical Association guidelines for research in humans [14]. An institutional ethics board approved the protocols.

\section{Pulmonary and respiratory muscle function tests}

Forced spirometry, inspiratory capacity (Datospir 92; SIBEL, Barcelona, Spain) and thoracic gas volume (Masterlab; Jaeger, Würzburg, Germany) measurements were made in each patient and compared to reference values from a Mediterranean population $[15,16]$. While patients breathed through a two-way valve (Hans Rudolph, Kansas City, MO, USA), maximal inspiratory oesophageal and transdiaphragmatic pressure during a maximal sniff manoeuvre at functional residual capacity were measured [17]. Maximal inspiratory pressure was measured using a manometer (BP1050; Biopac Systems, Goleta, CA, USA) with an occludable mouthpiece (SIBELMED, Sibel, Spain) according to the techniques described by BLACK and HYATT [18] and compared to the values of WILSON et al. [19]. Arterial blood samples were analysed for arterial oxygen $\left(\mathrm{Pa}, \mathrm{O}_{2}\right)$ and carbon dioxide tension $\left(\mathrm{Pa}_{\mathrm{a}} \mathrm{CO}_{2}\right)$ and $\mathrm{pH}$ (ABL 330; Radiometer, Copenhagen, Denmark). In addition, body weight was measured using an electronic beam scale with a digital readout to the nearest $0.1 \mathrm{~kg}$ with subjects standing barefoot and wearing light indoor clothing. Body height was measured to the nearest $0.1 \mathrm{~cm}$ and BMI (weight in kilograms divided by height in metres squared) calculated.

\section{Muscle biopsy}

In all COPD and control patients, biopsy specimens $(\sim 0.5 \mathrm{~cm} \times 0.5 \mathrm{~cm} \times 0.5 \mathrm{~cm})$ were obtained from the costal diaphragm at the beginning of the surgical procedure. In addition, in the COPD group, biopsy specimens were synchronously taken from the vastus lateralis. Diaphragm samples were taken from the apposition zone, $\sim 2 \mathrm{~cm}$ from the costodiaphragmatic angle at the mid-axillary line. Samples from the middle portion of the vastus lateralis were considered to be representative of the quadriceps muscle. Each biopsy specimen was divided into two pieces and these pieces randomly used for histomorphometric and biochemical analyses. The biopsy specimens were quick-frozen in isopentane, cooled in liquid nitrogen and stored at $-70^{\circ} \mathrm{C}$ until required for analysis.

\section{Histomorphometry}

Sections $(10 \mu \mathrm{m})$ of one piece of the muscle sample were obtained by adjusting the holder (in increments of $5^{\circ}$ ) until the minimum cross-sectional area (CSA) was obtained, which was defined as truly transverse for MyHC-I (CSA-I) and -II fibres (CSA-II) [20, 21]. Cross-sections were processed for immunohistochemical procedures [21]. CSA, mean least diameter and proportions of MyHC-I and -II fibres were assessed using a light microscope (Olympus, Series BX50F3; Olympus Optical Co., Tokyo, Japan) coupled to an image-digitising camera (Pixera studio, Version 1.2; Pixera Corporation, Los Gatos, CA, USA) using image analysis software (NIH Image, Version 1.60; Frederick, MD, USA). At least 100 fibres were measured per diaphragm and vastus lateralis biopsy specimen (mean number of fibres analysed 316 \pm 43$)$ [22, 23]. MyHC-I and -II monoclonal antibodies were used to identify MyHC-I and -II fibres (MHCs and MHCf clones; Biogenesis, Poole, UK) as described elsewhere [24].

\section{Muscle amino acid profile}

The remaining piece of frozen muscle tissue was deproteinised with sulphosalicylic acid for determination of amino acid concentrations. After adding glass beads $(1 \mathrm{~mm})$, the muscle tissue was homogenised using a Mini-beater (Biospec Products, Bartlesville, OK, USA). The amino acid profiles of the diaphragm and vastus lateralis were analysed in the same batch run by fully automated high-performance liquid chromatography (HPLC) $[25,26]$. Levels of the following amino acids were measured: glutamine, glycine, alanine, valine, isoleucine, leucine, phenylalanine, tyrosine, arginine, histidine, lysine, methionine, threonine, tryptophan, alphaaminobutyric acid, asparagine, citrulline, Glu, ornithine, serine, and taurine. The GSH concentration of the muscle specimen was assessed in the same HPLC run. The branchedchain amino acid concentration was calculated by summing the leucine, isoleucine and valine concentrations. The total amino acid concentration was also calculated.

\section{Statistical analysis}

Results are expressed as mean $\pm \mathrm{SD}$, and, in figures, amino acid and fibre type measurements are presented as mean \pm SEM. COPD and control group data were compared using an unpaired t-test. In order to assess whether muscle determination differences between the vastus lateralis and diaphragm in the COPD group were significant, a paired t-test (or Wilcoxon signed-rank test in the case of abnormal distribution) was used. A two-tailed probability value of $<0.05$ was considered significant. The relationships between muscle amino acid concentrations, GSH and fibre type distribution within each 
muscle group were studied by calculating Pearson's correlation coefficient (or Spearman's nonparametric correlation coefficient in the case of unequal variances).

\section{Results}

Nine patients with COPD (FEV1 $52 \pm 4 \%$ pred, range $28-68 \%$ pred) and seven controls (FEV1 $86 \pm 3 \%$ pred) participated in the study (table 1). Age, height, body weight and BMI did not differ between the two groups. The COPD group was characterised by lower FVCs $(\mathrm{p}<0.01)$ and higher residual volumes $(\mathrm{p}<0.05)$ than the control group. $\mathrm{Pa}, \mathrm{O}_{2}$ was lower in the COPD group than in the control group $(8.99 \pm 1.08$ versus $10.9 \pm 1.85 \mathrm{kPa}(67.6 \pm 8.1$ versus $81.7 \pm 13.9 \mathrm{mmHg})$, $\mathrm{p}<0.05) . P \mathrm{a}, \mathrm{CO}_{2}$ was higher in the COPD group $(5.49 \pm 0.36$ versus $4.81 \pm 0.36 \mathrm{kPa} \quad(41.3 \pm 2.7$ versus $36.2 \pm 2.7 \mathrm{mmHg})$, $\mathrm{p}<0.01)$. No difference was found in $\mathrm{pH}(7.43 \pm 0.03$ versus $7.42 \pm 0.01)$.

\section{COPD group versus controls}

No significant difference was found in the proportion of MyHC-I in the diaphragm between the COPD and control groups (table 1). Also, no difference was found in CSA-I and -II in the diaphragm between the COPD and control groups.

No difference was found in Glu (fig. 1a) and GSH concentration (fig. 1b) in the diaphragm between the COPD and control groups. In addition, the total amino acid concentration measured in the diaphragm did not differ between the control and COPD groups (fig. 1c).

\section{Diaphragm versus quadriceps femoris}

The COPD patients showed a higher proportion of MyHC-I in the diaphragm than in the quadriceps femoris $(70$ versus $26 \%, \mathrm{p}<0.001)$, and thus a lower proportion of MyHC-II (table 2). In the COPD group, CSA-I and -II did not differ between the diaphragm and quadriceps femoris.

Glu (fig. 1a) and GSH (fig. 1b) levels were significantly

Table 1.-General characteristics of study population

\begin{tabular}{lcc}
\hline & Controls & COPD group \\
\hline Subjects n & 7 & 9 \\
Age yrs & $65 \pm 3$ & $68 \pm 2$ \\
Height cm & $168 \pm 3$ & $167 \pm 2$ \\
Weight kg & $75.3 \pm 4.2$ & $73.4 \pm 4.3$ \\
BMI kg·m ${ }^{-2}$ & $26.5 \pm 1.0$ & $26.3 \pm 1.3$ \\
FEV1 \% pred & $86 \pm 3$ & $52 \pm 4^{* * *}$ \\
FVC \% pred & $84 \pm 2$ & $61 \pm 5^{* *}$ \\
TLC \% pred & $91 \pm 3$ & $102 \pm 7$ \\
RV \% pred & $100 \pm 9$ & $155 \pm 21^{*}$ \\
ITGV \% pred & $102 \pm 7$ & $129 \pm 17$ \\
$P \mathrm{I}, \mathrm{max} \%$ pred & $82 \pm 22$ & $86 \pm 26$ \\
$P$ oes,max $\mathrm{cmH}_{2} \mathrm{O}$ & $-76 \pm 14$ & $-67 \pm 22$ \\
$P$ di,max $\mathrm{cmH}_{2} \mathrm{O}$ & $99 \pm 19$ & $88 \pm 58$ \\
\hline
\end{tabular}

Data are presented as mean \pm SD. COPD: chronic obstructive pulmonary disease; BMI: body mass index; FEV1: forced expiratory volume in one second; FVC: forced vital capacity; TLC: total lung capacity; $\mathrm{RV}$ : residual volume; ITGV: intrathoracic gas volume; $P$ I,max: maximal inspiratory pressure measured at the mouth (Müller manoeuvre); Poes,max: maximal oesophageal pressure during sniff manoeuvre; $P$ di,max: maximal transdiaphragmatic pressure during sniff manoeuvre; $\%$ pred: percentage of the predicted value. $*$ : $\mathrm{p}<0.05 ; * *: \mathrm{p}<0.01 ; * * *$ : $\mathrm{p}<0.001$ versus controls.


Fig. 1.-Concentration of: a) glutamate (Glu); b) reduced glutathione (GSH); and c) total amino acids (TAAs) in the diaphragm (diaph) and quadriceps femoris (QF) of chronic obstructive pulmonary disease (COPD) patients $(\mathbb{Z})$ and control subjects $(\square)$. Data are presented as mean \pm SEM. WW: wet weight. *: $\mathrm{p}<0.05$ versus diaphragm in COPD.

lower in the quadriceps femoris than in the diaphragm $(p<0.05)$. The amino acid profiles of the diaphragm and quadriceps femoris are shown in table 3. Total amino acid concentration showed no difference between the two muscles (fig. 1c). Besides Glu, the levels of several other amino acids in the COPD group were lower in the quadriceps femoris than in the diaphragm. Furthermore, the Glu/GSH ratio was lower in the quadriceps femoris $(\mathrm{p}<0.05)$. However, no difference was observed for glutamine and taurine, amino acids that are generally present in very high concentrations in skeletal muscles. This may explain why there was no difference in the total amino acid concentration between the quadriceps femoris and the diaphragm in the COPD group. 
Table 2. - Size and distribution of fibre types in the diaphragm and quadriceps femoris ${ }^{\#}$

\begin{tabular}{lccc}
\hline & & \multicolumn{2}{c}{ COPD group } \\
\cline { 3 - 4 } & & Diaphragm & Vastus lateralis \\
\hline CSA-I $\mu \mathrm{m}^{2}$ & $3015 \pm 198$ & $3534 \pm 358$ & $3610 \pm 459$ \\
CSA-II $\mu \mathrm{m}^{2}$ & $3421 \pm 269$ & $3994 \pm 369$ & $3837 \pm 719$ \\
MyHC-I \% & $68.8 \pm 4.0$ & $70.2 \pm 3.0$ & $26.4 \pm 3.7 * * *$ \\
MyHC-II \% & $35.6 \pm 6.4$ & $29.8 \pm 3.0$ & $74.5 \pm 3.7 * * *$ \\
\hline
\end{tabular}

Data are presented as mean \pm SEM. COPD: chronic obstructive pulmonary disease; MyHC-I and -II: myosin heavy chain type I and type II; CSA-I and -II: cross-sectional area of MyHC-I and -II fibres, respectively. \#: vastus lateralis. ${ }^{* * *}: \mathrm{p}<0.001$ versus COPD group diaphragm.

\section{Correlations}

A highly significant correlation was found between muscle Glu and GSH levels (fig. 2c) in the diaphragm ( $\mathrm{r}=0.84$, $\mathrm{p}<0.01)$ and quadriceps femoris $(\mathrm{r}=0.88, \mathrm{p}<0.01)$. However, no significant relationship was found between intramuscular Glu or GSH level and fibre type distribution in either diaphragm (Glu r=-0.01; GSH r=-0.26, NS) or quadriceps femoris (Glu r=0.32; GSH r=0.29, NS) (fig. 2a and 2b). Total amino acid concentration was neither related to fibre type distribution nor CSA-I and -II in both muscles (data not shown). No relationship was evident between Glu or GSH levels and muscle fibre size (CSA-I or -II). Finally, levels of GSH and Glu (or other amino acids) of both the diaphragm and quadriceps femoris were not related to body weight or BMI (data not shown).

\section{Discussion}

This is the first study demonstrating that diaphragmatic levels of Glu and GSH do not differ between COPD patients and individuals with normal pulmonary function. Although it has previously been demonstrated that levels of Glu and GSH are reduced in the peripheral muscles of COPD patients, the present study demonstrates that such amino acid disturbance is not a generalised (systemic) phenomenon, suggesting that the diaphragm discloses amino acid adaptation in the face of the disease.

At first sight, it is surprising that the diaphragm, but not skeletal muscles, of COPD patients is able to preserve normal Glu and GSH levels. Respiratory and peripheral muscles are exposed to numerous factors that can negatively influence amino acid levels (malnutrition, inflammation, chronic hypoxaemia, drugs, etc.). However, the difference could be related to the fact that diaphragmatic myofibres are continuously working against the increased mechanical overload imposed by persistent airflow obstruction and pulmonary hyperinflation. This increased activity goes on for many years, and, therefore, structural changes can represent chronic diaphragmatic adaptations. If the mechanical loading imposed by the disease is able to emulate a training effect, preserved Glu and GSH levels could be considered adaptive metabolic changes within diaphragm cells. Indeed, peripheral muscle training has been shown to increase GSH and Glu content in healthy subjects $[4,27]$

A discrepancy may arise when comparing the chronic mechanical loading in the stable to that in the acute (exercise or exacerbation) state. It is well known that acute bouts of mechanical stress and factors such as free radicals, oxidation and increased protease activity are able to induce or

Table 3. - Free amino acid pool and glutathione (GSH) levels in the diaphragm and quadriceps femoris ${ }^{\#}$

\begin{tabular}{|c|c|c|c|}
\hline & \multirow[t]{2}{*}{ Control diaphragm } & \multicolumn{2}{|c|}{ COPD group } \\
\hline & & Diaphragm & Vastus lateralis \\
\hline Glu $\mu \mathrm{mol} \cdot \mathrm{kg} \mathrm{WW}^{-1}$ & $4161 \pm 588$ & $4253 \pm 558$ & $1584 \pm 333 *$ \\
\hline $\mathrm{GSH} \mu \mathrm{mol} \cdot \mathrm{kg} \mathrm{W^{-1 }}$ & $2257 \pm 160$ & $2140 \pm 228$ & $1226 \pm 201 *$ \\
\hline Glu/GSH & $1.8 \pm 1.5$ & $2.0 \pm 0.5$ & $1.3 \pm 0.1^{*}$ \\
\hline Asn $\mu \mathrm{mol} \cdot \mathrm{kg} \mathrm{WW}^{-1}$ & $282 \pm 8$ & $280 \pm 32$ & $157 \pm 23^{*}$ \\
\hline Ser $\mu \mathrm{mol} \cdot \mathrm{kg} \mathrm{WW}^{-1}$ & $650 \pm 102$ & $748 \pm 104$ & $451 \pm 79 *$ \\
\hline $\mathrm{Gln} \mu \mathrm{mol} \cdot \mathrm{kg} \mathrm{WW}^{-1}$ & $9328 \pm 898$ & $8808 \pm 1132$ & $9097 \pm 1306$ \\
\hline Gly $\mu \mathrm{mol} \cdot \mathrm{kg} \mathrm{WW}^{-1}$ & $1025 \pm 54$ & $966 \pm 78$ & $819 \pm 122$ \\
\hline Thr $\mu \mathrm{mol} \cdot \mathrm{kg} \mathrm{WW}^{-1}$ & $760 \pm 50$ & $812 \pm 91$ & $540 \pm 79 *$ \\
\hline $\mathrm{His} \mu \mathrm{mol} \cdot \mathrm{kg} \mathrm{WW}^{-1}$ & $394 \pm 49$ & $405 \pm 51$ & $339 \pm 59$ \\
\hline Cit $\mu \mathrm{mol} \cdot \mathrm{kg} \mathrm{WW}^{-1}$ & $87 \pm 17$ & $56 \pm 9$ & $106 \pm 26^{*}$ \\
\hline Ala $\mu \mathrm{mol} \cdot \mathrm{kg} \mathrm{WW}^{-1}$ & $2388 \pm 246$ & $2065 \pm 184$ & $1327 \pm 240^{* *}$ \\
\hline $\mathrm{Tau} \mu \mathrm{mol} \cdot \mathrm{kg} \mathrm{WW}^{-1}$ & $5835 \pm 697$ & $7031 \pm 759$ & $7332 \pm 1544$ \\
\hline $\operatorname{Arg} \mu \mathrm{mol} \cdot \mathrm{kg} \mathrm{WW}^{-1}$ & $442 \pm 66$ & $468 \pm 56$ & $375 \pm 90$ \\
\hline$\alpha-\mathrm{ABA} \mu \mathrm{mol} \cdot \mathrm{kg} \mathrm{WW}^{-1}$ & $56 \pm 7$ & $45 \pm 4$ & $37 \pm 6$ \\
\hline Tyr $\mu \mathrm{mol} \cdot \mathrm{kg} \mathrm{WW}^{-1}$ & $83 \pm 8$ & $99 \pm 9$ & $74 \pm 11^{+}$ \\
\hline Val $\mu \mathrm{mol} \cdot \mathrm{kg} \mathrm{WW}^{-1}$ & $341 \pm 35$ & $349 \pm 38$ & $271 \pm 32$ \\
\hline Met $\mu \mathrm{mol} \cdot \mathrm{kg} \mathrm{WW}^{-1}$ & $73 \pm 19$ & $83 \pm 20$ & $55 \pm 21$ \\
\hline Ile $\mu \mathrm{mol} \cdot \mathrm{kg} \mathrm{WW}^{-1}$ & $116 \pm 13$ & $118 \pm 13$ & $84 \pm 10$ \\
\hline Phe $\mu \mathrm{mol} \cdot \mathrm{kg} \mathrm{WW}^{-1}$ & $149 \pm 27$ & $124 \pm 14$ & $80 \pm 12^{\circ}$ \\
\hline Trp $\mu \mathrm{mol} \cdot \mathrm{kg} \mathrm{WW}^{-1}$ & $324 \pm 49$ & $315 \pm 80$ & $184 \pm 35$ \\
\hline Leu $\mu \mathrm{mol} \cdot \mathrm{kg} \mathrm{WW}^{-1}$ & $208 \pm 24$ & $184 \pm 14$ & $140 \pm 19 *$ \\
\hline Orn $\mu \mathrm{mol} \cdot \mathrm{kg} \mathrm{WW}^{-1}$ & $154 \pm 18$ & $155 \pm 19$ & $163 \pm 44$ \\
\hline Lys $\mu \mathrm{mol} \cdot \mathrm{kg} \mathrm{WW}^{-1}$ & $693 \pm 75$ & $690 \pm 95$ & $694 \pm 176$ \\
\hline BCAAs $\mu \mathrm{mol} \cdot \mathrm{kg} \mathrm{WW}^{-1}$ & $633 \pm 65$ & $651 \pm 60$ & $493 \pm 66$ \\
\hline Total AAs $\mu \mathrm{mol} \cdot \mathrm{kg} \mathrm{WW}^{-1}$ & $30467 \pm 3049$ & $31729 \pm 3091$ & $28836 \pm 4388$ \\
\hline
\end{tabular}

Data are presented as mean \pm SEM. COPD: chronic obstructive pulmonary disease; Glu: glutamate; GSH: reduced glutathione; Asn: asparagines; Ser: serine; Gln: glutamine; Gly: glycine; Thr: threonine; His: histidine; Cit: citrulline; Ala: alanine; Tau: taurine; Arg: arginine; $\alpha$-ABA: alphaaminobutyric acid; Tyr: tyrosine; Val: valine; Met: methionine; Ile: isoleucine; Phe: phenylalanine; Trp: tryptophan; Leu: leucine; Orn: ornithine; Lys: lysine; BCAA: branched-chain amino acid (AA); WW: wet weight. ${ }^{*}$ : vastus lateralis. ๆ: $\mathrm{p}=0.08 ;{ }^{+}$: $\mathrm{p}=0.07 ;{ }^{*}: \mathrm{p}<0.05 ;{ }^{* *}$ : $\mathrm{p}<0.01$ versus $\mathrm{COPD}$ group diaphragm. 

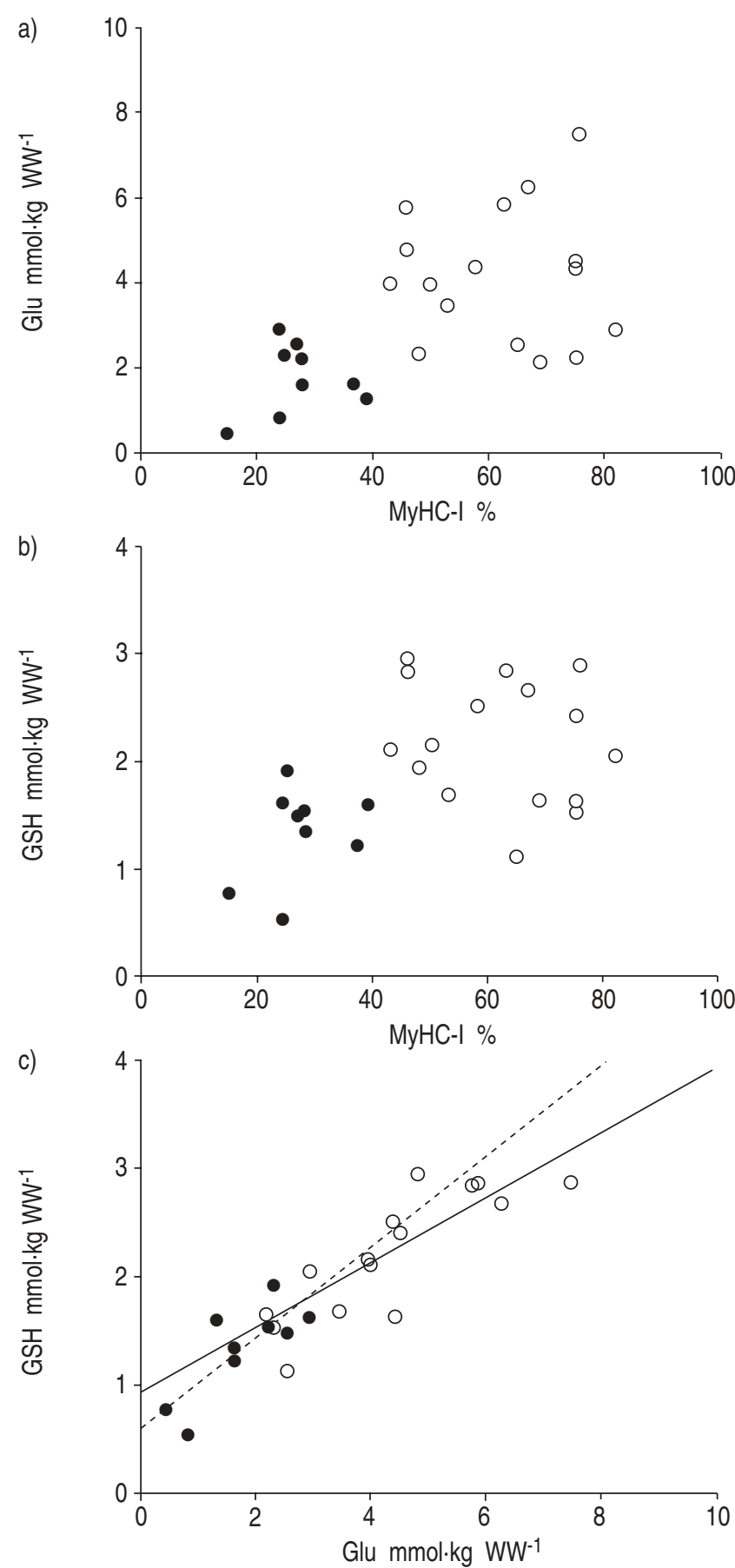

Fig. 2. - Scatter plots showing correlation between: a) proportion of myosin heavy chain type I (MyHC-I) fibres and muscle glutamate (Glu) levels; b) proportion of MyHC-I fibres and muscle reduced glutathione (GSH) levels; and c) muscle Glu and GSH levels in quadriceps femoris $(\bullet)$ and diaphragm $(\bigcirc)$. Regression lines for quadriceps femoris (- - ) and diaphragm (-) are shown in c). WW: wet weight.

accentuate diaphragm injury [28-30]. There is evidence for increased systemic oxidative stress in COPD patients during exercise, and, perhaps, even at rest [31, 32], indicating the importance of optimisation of muscle antioxidant levels in COPD. Some recent evidence permits the suggestion to be made that the present findings showing a preserved level of Glu and GSH in the diaphragm could be suboptimal in the setting of severe COPD. Indeed, increased susceptibility to diaphragm injury has been found in COPD patients submitted to acute inspiratory loading [5]. It was recently shown that the diaphragm of COPD patients exhibits up to $300 \%$ greater susceptibility to injury (as assessed by sarcomere disruption) compared to that of control subjects [5]. Besides a negative morphological effect, an acute bout of exercise is also known to negatively influence muscle amino acid metabolism in COPD. Recently, it was shown that 20 min of moderateintensity exercise resulted in depletion of the skeletal muscle amino acid pool, including that of Glu [1]. Further research is needed to test whether this also holds for acute respiratory muscle loading.

\section{Glutamate concentration in relation to fibre type}

The high proportion of MyHC-I fibres present in the diaphragm of the COPD group $(70 \%)$ and low proportion of MyHC-I in the quadriceps femoris $(26 \%)$ were in line with earlier data $[6,7,10]$. There is a IIb/x to I shift towards more oxidative metabolism in the diaphragm, and a I to IIb/x shift towards less oxidative metabolism in the lower limb muscle of patients with COPD. To date, two studies examining the relationship between amino acid profile and fibre typing of muscle have been conducted $[11,12]$. In rats, fast-twitch muscles (plantaris and gastrocnemius) show lower levels of a few amino acids (including Glu) but higher levels of other amino acids compared to slow-twitch muscles (soleus) [11]. Different results were obtained in a recent study in which the amino acid profile was examined in separate pools of different (single) fibre types of the vastus lateralis muscle of five endurance-trained humans [12]. This study showed that the Glu concentration is 9\% higher in MyHC-II than in MyHC-I fibres, whereas comparable values can be found for most of the remaining amino acids.

In the present study, Glu levels were $63 \%$ higher in the diaphragm (30\% MyHC-II fibres) than in the quadriceps femoris (74\% MyHC-II fibres) of COPD patients. This suggests that the differences in Glu concentration are likely to be $>63 \%$ in the separate pools of fibre types in COPD. In addition, no significant relationship was found between levels of Glu or total amino acids and proportions of $\mathrm{MyHC}$ fibres in both quadriceps femoris and diaphragm. These findings demonstrate that the low proportion of MyHC-I fibres is not responsible for the reduced Glu level which has consistently been observed in the peripheral skeletal muscle of patients with COPD [1, 3, 33]. Factors other than fibre type distribution play a significant role in the observed differences in Glu levels (and total amino acid profile) between the two muscle groups in COPD.

\section{Glutathione concentration in relation to fibre type}

In the present study, the absolute GSH concentration was $42 \%$ higher in the diaphragm than in the quadriceps femoris of patients with COPD. However, no significant relationship was found between GSH levels and the proportion of MyHCI. This suggests that other factors, in addition to a reduced oxidative capacity, are responsible for the observed reduction in GSH concentration in the peripheral muscles in COPD. RABINOVICH et al. [27] recently showed that endurance training did not increase GSH levels in the peripheral muscle of patients with COPD. The present data are in line with their findings, suggesting that enhancement of the oxidative capacity of muscle may not be fully successful in protecting against oxidative stress in COPD patients.

The proportion of MyHC-I fibres in the non-COPD group 
is somewhat higher than those previously reported by NGUYEN et al. [34] and LeVINE and coworkers [6, 35] (45 and $41 \%$ ). This may be related to differences in the criteria used for selection of a control group. In the present study, it was decided to include subjects with localised lung neoplasm. The possibility that the presence of lung cancer contributes to the slightly higher level of MyHC-I fibres in the diaphragm cannot be totally excluded, although the exact underlying mechanism is difficult to elucidate. NGUYEN et al. [34] and LEVINE and coworkers [6, 35] included subjects with mild pulmonary impairment undergoing resection of solitary pulmonary nodules and brain-dead organ donors. It is possible that both the underlying lung diseases in the first group and the amount of time in receipt of ventilatory support and the decreased central ventilatory drive due to brain death in the second group may be an important bias. Furthermore, sex differences between the studies may possibly contribute to the small differences in fibre typing between the control groups. Whereas the present study included only male patients, NGUYen et al. [34] and LeVINE and coworkers [6, 35] conducted studies in which 70,100 and $65 \%$ of the study population were female. More studies are needed to confirm whether sex indeed plays a role in fibre type distribution in diaphragm muscle.

\section{Glutamate concentration in relation to glutathione concentration}

To the present authors' knowledge, this is the first study reporting amino acid concentrations in the diaphragm of subjects with normal lung function and patients with COPD. Higher levels of Glu were found in the diaphragm compared to the quadriceps femoris of patients with COPD. The levels of several other amino acids (i.e. alanine, serine, threonine and leucine) were also higher in the diaphragm than in the quadriceps femoris. Moreover, the mean difference in total amino acid concentration $(9 \%)$ was much smaller than that of Glu $(63 \%)$. However, it is beyond the scope of the present article to discuss these differences further.

In the present study, Glu concentration was highly correlated with GSH concentration in quadriceps femoris, which is in agreement with previous data [3]. Moreover, in the diaphragm, a comparably high correlation coefficient was also found between Glu and GSH concentration. These data suggest that muscle Glu is an important precursor for the first and rate-limiting step in the synthesis of the antioxidant GSH, independent of the muscle group studied (diaphragm versus lower limb muscles).

\section{Potential limitations of the present study}

In the present study, neither the levels of amino acids nor the histomorphometric characteristics of the quadriceps femoris were assessed in the control volunteers. From a methodological point of view, it is acknowledged that inclusion of control values for Glu concentration in the quadriceps femoris could have been complementary data. However, the lack of such data does not affect the main aim or conclusions of the present study. The present results are consistent with other studies assessing amino acid levels in the peripheral muscles of COPD patients. Although the quadriceps femoris of the COPD group showed comparable levels of Glu to those observed in other settings, these levels were lower than those described in the quadriceps femoris of healthy controls $[1,3,33]$. It should also be mentioned that, although the histomorphological and biochemical analysis utilised individual segments of muscle, both of the two segments originated from the same biopsy specimen. Furthermore, the variation in the biochemical and histomorphometric analyses ranged $13-21$ and $4-14 \%$, respectively. These findings suggest a low likelihood that the muscle samples used for the distinctive analyses were not representative of each other. Finally, as the Glu and GSH concentrations were expressed per kilogram of wet weight, the data could be influenced by differences in water content between the study groups. In the present study, the water content of the muscle samples was not measured, but, instead, data from a previous study were reassessed [33]. No significant difference was found in water content between muscle samples from COPD patients $(77.0 \pm 0.7 \%, n=31)$ and control volunteers $(77.3 \pm 0.7 \%, n=26)$.

\section{Conclusions}

The present study illustrates that glutamate and reduced glutathione levels are preserved in the diaphragm of chronic obstructive pulmonary disease patients, suggesting that the diaphragm has the capacity to show adaptive metabolic changes and is relatively "protected" against disease-related disturbances in amino acid and thus protein metabolism. Disturbances in glutamate and reduced glutathione metabolism are muscle-specific in chronic obstructive pulmonary disease, affecting the quadriceps femoris but not the diaphragm. Glutamate and reduced glutathione levels are strongly interrelated in both muscles but independent of fibre type distribution and fibre size.

\section{References}

1. Engelen MPKJ, Wouters EFM, Deutz NEP, Does JD, Schols AMWJ. Effects of exercise on amino acid metabolism in patients with chronic obstructive pulmonary disease. $\mathrm{Am}$ J Respir Crit Care Med 2001; 163: 859-864.

2. Pouw EM, Schols AMWJ, Deutz NEP, Wouters EFM. Plasma and muscle amino-acid levels in relation to resting energy expenditure and inflammation in stable COPD. Am J Respir Crit Care Med 1998; 158: 797-801.

3. Engelen MPKJ, Schols AMWJ, Does JD, Deutz NEP, Wouters EFM. Altered glutamate metabolism is associated with reduced muscle glutathione levels in patients with emphysema. Am J Respir Crit Care Med 2000; 161: 98-103.

4. Engelen MPKJ, Schols AMWJ, Does JD, Gosker HR, Deutz NEP, Wouters EFM. Exercise-induced lactate increase in relation to muscle substrates in patients with chronic obstructive pulmonary disease. Am J Respir Crit Care Med 2000; 162: 1697-1704.

5. Orozco-Levi M, Lloreta J, Minguella J, Serrano S, Broquetas JM, Gea J. Injury of the human diaphragm associated with exertion and chronic obstructive pulmonary disease. Am J Respir Crit Care Med 2001; 164: 1734-1739.

6. Levine S, Kaiser L, Leferovich J, Tikunov B. Cellular adaptations in the diaphragm in chronic obstructive pulmonary disease. N Engl J Med 1997; 337: 1799-1806.

7. Whittom F, Jobin J, Simard PM, et al. Histochemical and morphological characteristics of the vastus lateralis muscle in patients with chronic obstructive pulmonary disease. Med Sci Sports Exerc 1998; 30: 1467-1474.

8. Satta A, Migliori GB, Spanevello A, et al. Fibre types in skeletal muscles of chronic obstructive pulmonary disease patients related to respiratory function and exercise tolerance. Eur Respir J 1997; 10: 2853-2860.

9. Jakobsson P, Jorfeldt L, Brundin A. Skeletal muscle metabolites and fibre types in patients with advanced chronic obstructive pulmonary disease (COPD), with and without chronic respiratory failure. Eur Respir J 1990; 3: 192-196. 
10. Maltais F, Sullivan MJ, LeBlanc P, et al. Altered expression of myosin heavy chain in the vastus lateralis muscle in patients with COPD. Eur Respir J 1999; 13: 850-854.

11. Turinsky J, Long CL. Free amino acids in muscle: effect of muscle fiber population and denervation. Am J Physiol 1990; 258: E485-E491.

12. Essen-Gustavsson B, Blomstrand E. Effect of exercise on concentrations of free amino acids in pools of type I and type II fibres in human muscle with reduced glycogen stores. Acta Physiol Scand 2002; 174: 275-281.

13. Siafakas NM, Vermeire $\mathrm{P}$, Pride $\mathrm{NB}$, et al. Optimal assessment and management of chronic obstructive pulmonary disease (COPD). Eur Respir J 1995; 8: 1398-1420.

14. World Medical Association. Declaration of Helsinki: Ethical Principles for Medical Research Involving Human Subjects. Washington, DC, World Medical Association, 2002.

15. Roca J, Sanchis J, Agusti-Vidal A, et al. Spirometric reference values from a Mediterranean population. Bull Eur Physiopathol Respir 1986; 22: 217-224.

16. Roca J, Rodriguez-Roisin R, Cobo E, Burgos F, Perez J, Clausen JL. Single-breath carbon monoxide diffusing capacity prediction equations from a Mediterranean population. Am Rev Respir Dis 1990; 141: 1026-1032.

17. Aran X, Gea J, Guiu R, Aguar MC, Sauleda J, Broquetas JM. Comparison between three different manoeuvres for achieving maximal transdiaphragmatic pressures. Arch Bronconeumol 1992; 28: 112-115.

18. Black LF, Hyatt RE. Maximal respiratory values: normal values and relationship to age and sex. Am Rev Respir Dis 1969; 99: 696-702.

19. Wilson SH, Cooke NT, Edwards RH, Spiro SG. Predicted normal values for maximal respiratory pressures in Caucasian adults and children. Thorax 1984; 39: 535-538.

20. Dubowitz V, Brooke MH. Muscle biopsy: a modern approach. In: Dubowitz V, Brooke MH, eds. Major Problems in Neurology. London, Saunders, 1973; pp. 74-85.

21. Poole DC, Lieber RL, Mathieu-Costello O. Myosin and actin filament lengths in diaphragms from emphysematous hamsters. J Appl Physiol 1994; 76: 1220-1225.

22. Brooke MH, Engel WK. The histographic analysis of human muscle biopsies with regard to fiber types. 1. Adult male and female. Neurology 1969; 19: 221-233.

23. Hards JM, Reid WD, Pardy RL, Pare PD. Respiratory muscle fiber morphometry. Correlation with pulmonary function and nutrition. Chest 1990; 97: 1037-1044.

24. Ramirez-Sarmiento A, Orozco-Levi M, Guell R, et al.
Inspiratory muscle training in patients with chronic obstructive pulmonary disease: structural adaptation and physiologic outcomes. Am J Respir Crit Care Med 2002; 166: 1491-1497.

25. Van Eijk HM, van der Heijden MA, van Berlo CL, Soeters PB. Fully automated liquid-chromatographic determination of amino acids. Clin Chem 1988; 34: 2510-2513.

26. Van Eijk HMH, Rooyakkers DR, Deutz NEP. Rapid routine determination of amino acids in plasma by highperformance liquid chromatography with a 2-3 microns Spherisorb ODS II column. J Chromatogr 1993; 620: 143148.

27. Rabinovich RA, Ardite E, Troosters T, et al. Reduced muscle redox capacity after endurance training in patients with chronic obstructive pulmonary disease. Am J Respir Crit Care Med 2001; 164: 1114-1118.

28. Orozco-Levi M, Gea J, Lloreta JL, et al. Subcellular adaptation of the human diaphragm in chronic obstructive pulmonary disease. Eur Respir J 1999; 13: 371-378.

29. Belcastro AN, Shewchuk LD, Raj DA. Exercise-induced muscle injury: a calpain hypothesis. Mol Cell Biochem 1998; 179: 135-145.

30. Jiang TX, Reid WD, Belcastro A, Road JD. Load dependence of secondary diaphragm inflammation and injury after acute inspiratory loading. Am J Respir Crit Care Med 1998; 157: 230-236.

31. Heunks LM, Vina J, van Herwaarden CL, Folgering HT, Gimeno A, Dekhuijzen PN. Xanthine oxidase is involved in exercise-induced oxidative stress in chronic obstructive pulmonary disease. Am J Physiol 1999; 277: R1697-R1704.

32. Vina J, Servera E, Asensi M, et al. Exercise causes blood glutathione oxidation in chronic obstructive pulmonary disease: prevention by $\mathrm{O}_{2}$ therapy. J Appl Physiol 1996; 81: 2199-2202.

33. Engelen MPKJ, Wouters EFM, Deutz NEP, Menheere PP, Schols AMWJ. Factors contributing to alterations in skeletal muscle and plasma amino acid profiles in patients with chronic obstructive pulmonary disease. Am J Clin Nutr 2000; 72: $1480-1487$.

34. Nguyen T, Shrager J, Kaiser L, et al. Developmental myosin heavy chains in the adult human diaphragm: coexpression patterns and effect of COPD. J Appl Physiol 2000; 88: 14461456.

35. Levine S, Gregory C, Nguyen $\mathrm{T}$, et al. Bioenergetic adaptation of individual human diaphragmatic myofibers to severe COPD. J Appl Physiol 2002; 92: 1205-1213. 